\section{ALOPECIA AND SEBORRHEA *}

CHARLES J. WHITE, M.D.

Instructor in Dermatology in Harvard University BOS'TON

Dandruff and loss of hair are two of the minor afflictions of civilized life which are usually sources of constant chagrin to the unfortunate men and women who fall victims to their presence. One or both of these conditions, which even we ourselves experience sooner or later, are brought to our attention as dermatologists sn frequently that it seems fitting from time to time to present them as themes for discussion when we. meet in the hope that some member here may contribute some small bit of knowledge to a subject which needs so much help from an etiologic and therapeutic standpoint. It is, therefore, because we practitioners are usually so helpless when confronted by a well-established case of alopecia or of seborrhea that I have ventured to summarize my knowledge of these conditions gleaned from the study of 794 examples observed in my personal private practice.

In the following pages I shall deal principally with seborrhea capitis and with alopecia simplex and alopecia furfuracea, but I shall speak superficially on alopecia areata, and alopecia from ringworm, syphilis and overexposure to $x$-rays.

\section{ALOPECIA}

Statistically, T record 679 cases of loss of hair divided clinically as follows:

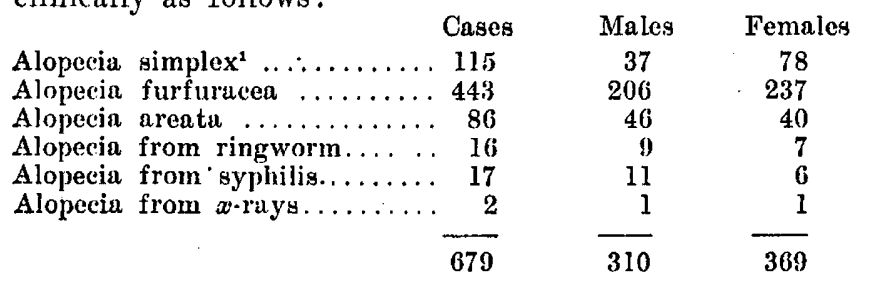

From these figures it will be seen that women are more often affected by loss of hair than men, in the relative proportion of 54 and 46 , unless it be that women teel this loss more keenly and therefore consult physicians more freely on this account. It is interesting, however, to note the figures of Elliot, ${ }^{2}$ who in his paper of 1892 records about jdentical percentages, viz. 55 per cent. women and 44 per cent. men. Jackson, ${ }^{3}$ on the other hand, in 1893 found the proportions reversed and recorded alopecia in 52 per cent. males and 48 per cent. females.

\section{Possible Etiologic Factors in Alopecia Simplex and Alopecia Furfuracea}

From a study of my records it will be noted that heredity, dandruff, systemic depression, fever, operations and maltreatment of the scalp have been connected in the patients' minds with the production of the fall of the hair. Under the heading of systemic depression figure overwork, worry, nervous exhaustion and prostration, recent immigration or foreign travel, pregnancies, and chronic diseases or invalidism. 'The term "maltreatment of the scalp" is based on my own per-

- Read in the Section on Dermatology of the Ameriean Medical Association; at the Sixty-di'st Annual Session, held at St. Louls, June, 1910 .

1. Iy this telm is meant the simple loss of hair without other objectlve symptoms.

2. Nillot, G. 'T.: Stxteenth Annual Meeting of Am. Derm. Assn.; see report, p. 81.

3. Jackson, G. T. : Loss of Hair, a Clinleal Study Folmed in 300 Frivate Cuses, Tr. Ain. Dermat. Assn., 1000, p. 50. sonal theories as to what is right and what is wrong in the hygiene of the scalp and includes the rough usage of brushes, combs and massage in the presence of dandruff; shampoos less often than once a month or more frequently than once a week; the use of any drugs in any form on the healthy hair or scalp; the continued application of too drying alkaline soaps; the frequent or constant exposure of the uncovered head to the summer sun; the daily sousing of the head in shower-baths or in salt water; and the modern over-treatment of the normal scalp by barbers and hairdressers.

Statistically we find these factors summed up as follows :

Heredity: Father's side of the house $\ldots \ldots \ldots \ldots \ldots \ldots, 108$
Mother's side of the house $\ldots \ldots \ldots \ldots \ldots \ldots, 51$
Not recorded $\ldots \ldots \ldots \ldots \ldots \ldots \ldots, \frac{12}{171}$

Alopecia present in brothers or sisters.......... 72

From these figures it is seen that a hereditary taint exists in 30 per cent. of these individuals. Dandruff was present in 443 patients, a percentage of $79+$. Systemic depression was recorded in 120 cases, a percentage of $21+$. Fever was noted in 63 individuals, a percentage of $11+$. Operations were blamed in 12 persons, a percentage of $2+$. Maltreatment was evident in $27 \%$ patients, a percentage of nearly 50 ; and, finally, more than one of the above possible etiologic factors was found in 386 cases, a percentage of approximately 70 .

It may be interesting to pause a moment and compare these figures with those of Dr. G. T. Elliot ${ }^{4}$ and of Dr. G. T. Jackson ${ }^{3}$ who based their figures on 344 and 300 cases respectively.

Heredity Systemic Causes Seborrhea

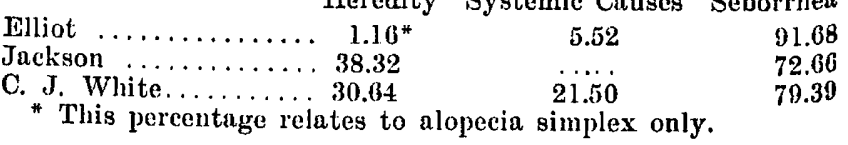

The figures which follow in the rest of this paper are not wholly satisfactory and are comparatively small, as the symptoms had existed so long in many cases that patients were unable to remember the exact date of their beginnings.

\section{Ages When Alopecia Simplex First Appeared}

Among those who could be exact there were 25 males and 43 females out of a possible 37 and 78 respectively.

Malos: 7 cases began between 16 and 20 .

8 cases began between 21 and 25 .

6 cases began between 26 and 30 .

1 case began at 35 .

1 case began at 39 .

2 cases began at 46 .

It will be seen that this clinically uncomplicated type of loss of hair begins at or before the age of 30 in 84 per cent. of the male cases.

Females: 7 cases began at or before the age of 15 .

3 cases began between 16 and 20 .

5 enses began between 21 and 25 .

4 cases began between 26 and 30 .

7 cases began between 31 and 35 .

2 cases began between 36 and 40 .

6 cases began between 41 and 45 .

6 cases began between 46 and 50 .

2 cases began between 51 and 55 .

1 case began at or before the age of 56 .

4. Hallot, G. T.: Alopecla and Its Most Frequent Cause, Derma titis Seborrbelca, Tr. Am. Dermat. AsBn., 1805, p. 05. 
Of the seven early cases five followed acute febrile disturbances. Between the ages of $\mathbf{1 5}$ and 30 , however, we find that 33 per cent. of these women developed their simple alopecia, contrasted with a respective percentage of 84 in men, whereas between the ages of 31 and 50 we note a percentage of 58 , figures which force us to the conclusion that alopecia simplex develops much later in women than in men.

\section{Ages When Dandruff and Alopecia Appeared in Alope- cia Furfuracea}

DANBRUFF

Males, 91 cases.

3 cases began between 9 and 10

8 cases began between 11 and 15

31 eases bearll between 16 and 20

25 cases began between 21 and 25

14 cases began between 26 and 30

8 cases began between 31 and 35

1 ease began at 37 and 1 at 43

Females, 75 cases.

3 cases began between 7 and 10
12 cases began between 11 and 15
10 cases began between 16 and 20
13 cases began between 21 and 25
11 cases began between 26 and 30
12 cases began between 31 and 35
7 cases began between 30 and 40
3 cases began between 42 and 45
4 cases began between 40 and 50

Contrasting these two columns of statisties we are struck by two facts, viz., that men are more prone to remember the exact date wlien their dandruff began than is the case with women and that in these men and women seborrhea capitis appeared at an earlier perjod in the former sex than in the latter. Thus between the years 16 and 25 we find 61 per cent. of males developing their dandruff whike in females at a similar epoch we find but 32 per cent.

Males, 127 cases.
6 cases began between 10 and 15
30 cases began between 16 and 20
55 cases began between 21 and 25
14 cases began between 26 and 30
14 cases began between 31 and 35
2 cases began between 36 and 40
3 cases began between 41 and 45
2 cases began between 46 and 50
1 case began at 60

Females, 129 cases.

7 cases began between 12 and 15
24 cases began between 16 and 20
21 cases began between 21 and 25
25 cases began between 20 and 30
25 cases began between 31 and 35
16 cases began between 36 and 40
5 cases began between 41 and 45
1 each at $46,51,54,61,63$ and 68

In these columns it is seen that men and women are apparently equally impressed by the exact age at which their hair begins to fall but that between the ages of 16 and 25 alopecia develops in 67 per cent. of the men affected against 34 per: cent. in the women.

Thus from these foregoing contrasting figures we learn that men are attacked much earlier than the opposite sex by alopecia furfuracea whereas women, as a whole become the victims of alopecia, either simple or furfuraceous, more often than men, in fact, in the proportion of 56 to 43.
Varieties, Distribution, and Subjective Symptoms of Dandruff and Loss of Hair in Alopecia Frurfuracea

\begin{tabular}{|c|c|c|}
\hline DANDRUFF & & ALOIECIA \\
\hline Slight in & ises. & Jases. \\
\hline Abundant in & & Slight in \\
\hline $\begin{array}{l}\text { ADundant in } \\
\text { Localized in }\end{array}$ & 199 & Marked in \\
\hline Yellow-brown & 83 & General in \\
\hline Oily in ...... & 50 & Principally on foreheal \\
\hline $\begin{array}{l}\text { Omy in } \\
\text { Jry in }\end{array}$ & $\begin{array}{l}78 \\
59\end{array}$ & in $\ldots . .$. \\
\hline Granular in & 53 & on top \\
\hline Adlerent in & 23 & $\cdots \cdots \cdots$ \\
\hline Loose and large in & 38 & Principally on sicles in. \\
\hline Accompanied by pruritus & 39 & $\begin{array}{l}\text { Principally at tonsure in } \\
\text { Hair dry in }\end{array}$ \\
\hline & 97 & Hair greasy in. \\
\hline Accompanied by burning & & Hair split in ...... \\
\hline mied by & 3 & Hair short in........ \\
\hline$\ldots \ldots \ldots$ & 30 & $\begin{array}{l}\text { Hair coarse in } \ldots \ldots \ldots \ldots \\
\text { Hair fine in } \ldots \ldots \ldots \ldots\end{array}$ \\
\hline
\end{tabular}

These figures require no elucidation. It is evident from their study that in alopecia furfuracea we may expect to encounter more often well-marked examples of seborrhea and of loss of hair than the reverse; that dandruff is usually general in distribution, while alopecia is generally localized; that dandruff is frequently accompanied by subjective symptoms and is often associated very strikingly with many changes in the texture of the hair as well as in its loss.

\section{The Treatment of Alopecia Furfuracea}

I fear that we must all agree that our therapeutic results in this disease are very disheartening. I tell all my pationts who have noted this condition for more than a few months, and especially those whose forebears have been similarly affected, that a permanent cure is hardly to be hoped for, but that by long and continued perseverance on their part they may keep their scalps clean and delay the inevitable baldness for years.

The medical aphorism which tells us that therapentic non-success may be judged by the multiplicity of the drugs recommended in a given disease is well emphasized in the present instance.

My armamentarium has included the following medicaments :

Washes, containing 70 per cent. alcohol, quinin, cantlarides, capsicum, pilocarpin, chloral lydrate, tartaric and salicylic acids, phenol, formaldehyd, trikresol, anthrasol, and croton
and turpentine oils.

Ointments, containing sulphur, salicylic acid, zinc oxid, resorcin, oil of cade, ichthyol, succus limonis, yellow oxid and ammoniated chlorid of mercury, orthoform and biborate of soda.

Soaps, containing betanaphthol and glycerin.

Internal medication, including iron, nux vomica, magnesium sulphate, dilute sulphuric acid, betanaphthol, malt, cod-liver oil, phenyl salicylate, ichthyol, salicin, thyroid extract and phosphate of soda.

Massage.

Despite this long list I practically confine myself to four prescriptions which I append:

1. $R$. gm. or c.c.

Acid. salicyl $\ldots \ldots \ldots \ldots \ldots \ldots \ldots \ldots$

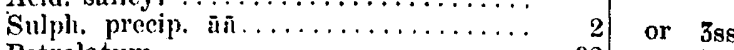

Petrolatum $\ldots \ldots \ldots \ldots \ldots \ldots \ldots \ldots .32$ or $3 \mathrm{j}$

M. S.-Ointment. Apply at night. Shampoo with a simple sonp the following day.

2. R. gm. or c.e.

Pilocarpin nitrat. $\ldots \ldots \ldots \ldots \ldots \ldots \ldots, \quad 06 \quad$ gr. $i$ Quinin sulph. $\ldots \ldots \ldots \ldots \ldots \ldots \ldots \ldots, \quad \int_{0}$ or $\begin{aligned} & \mathrm{gr} .1 \\ & \mathrm{gr} . \mathrm{x}\end{aligned}$ Tr. canthar.

Tr. capsic. niñ................

Alcohol, 70 per cent. ad.......... 250 fl. \$viii

M. S.-Wash for scalp. Apply in the morning. 
3. R.

Acid tannic ................ $2 \mid 26 \mathrm{gr}, \mathbf{x x x v}$

Chloral liydrate .............. 160 gr. xxvi

Acid tartaric $\ldots \ldots \ldots \ldots \ldots \ldots \ldots$ 2 2 gr. $\mathrm{xxx}$

Ol. ricini $\ldots \ldots \ldots \ldots \ldots \ldots \ldots \ldots$ r or $\mathrm{m} . \mathrm{xv}$

Alcohol, 70 per cent......... 200 fl. Zैvi

M. S.-Wash for scalp. Apply in the morning.

4. $\mathrm{R}$.

Hydrarg. chlorid. corrosiv...........

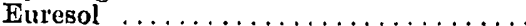

Sp. formicarum $\ldots \ldots \ldots \ldots \ldots \ldots \ldots$

Ol. ricini

M. S.-Wash for scalp (poison). Apply two teaspoonfuls in the morning.

The last of these four I hold easily first in its successful results. I associate its formula with $\mathrm{Dr}$. G. T. Illiot, and it has proved a veritable godsend to me in treating many of these almost impossible cases. The essential feature in its composition is, I believe, euresol - the mono-acetate of resorcin. The smell of this salt is a very unfortunate factor, however, but one which the manufacturers have not been able to eradicate without markedly diminishing the value of the drug. The elloralhydrate wash I place second in efficacy.

Perhaps the most striking feature of these four prescriptions seems to be the absence of pure resorcin from their composition. I am flee to confess that I never have been able to reduce its strength sufficiently to render it anything but an irritant to the scalp.

Results of Treatment Summarized by Age Males, 200 cases

Very good, 10 cases

\begin{tabular}{|c|c|c|}
\hline At & 19 & 2 cases \\
\hline Between & 20 and 25 , & 4 cases \\
\hline Between & 26 and 30 , & 3 cases \\
\hline At & 31 & 1 case \\
\hline Between & 41 and 45 , & 3 cases \\
\hline Between & 40 and 50 , & 2 cases \\
\hline At & 58 & 1 case \\
\hline
\end{tabular}

Good, 80 cases

At 13 and 14, 2 cises Between 16 and 20, 10 cases Between 21 and 25,16 cases Between 20 and 30,23 cases Between 31 and 35,13 cases Between 36 and 40,9 cases Between 41 and 45, 3 cases At $49,56,65$ and 75,1 case FEMALES, 194 CASES

Very good, 17 cases

At $13 \quad 1$ case

Between 26 and 30,4 cases

Between 31 and 35, 5 cases

At $\quad 38 \quad 2$ cases

Between 47 and 50, 3 cases

Between 56 and 60,2 cases

Slight, 53 cases

Between 5 and 9, 2 cases Between 13 and 15, 4 cases Between 16 and 20,2 cases Between 21 and 25, 11 cases Between 26 and 30,11 cases Between 31 and 35,7 cases Between 36 and 40,4 cases Between 41 and 45,3 cuses Between 46 and 50, 5 cases Between 51 and 55, 2 cases At $\quad 70 \quad 2$ cases Bad, 6 cases

At $15 \quad 1$ case

Between 30 and 37,2 cases Between 43 and 48,3 cases gm. or c.c.

gm. or c.c.

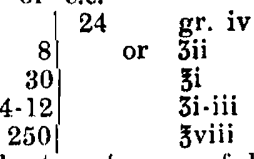

\section{Slight, 58 cuses}

Between 15 and 20, 10 cases Between 21 and 25, 20 cases Between 26 and 30,13 cases Between 31 and 35, 6 cases Between 30 and 40,2 cases lietween 41 and 50,4 cnses Between 53 and 63,3 cases

\section{Poor, 37 cases}

At 18 and 10, 2 cases Between 21 and 25, 14 cases Between 26 and 30,8 cases

Between 20 and 26,4 canses At $32 \quad 2$ cassos

These figures are comparatively small because many patients came but once and hence cannot be included in these lists.

From these figures it is seen that the prognosis in women is better than in men in the proportion of 56 per cent. to 48 per cent. These percentages are based on the "very good" and the "good" results in both sexes; and in addition we see that there were fewer "poor" and "bad" results in women than in the men in the proportion of 16 per cent. to 23 per cent. Therefore, we may encourage our feminine patients decidedly more than we can our masculine.

\section{SEBORRHEA}

Included in this study of 794 cases were found 117 individuals who were the subjects of dandruff alone. It is rather a disconcerting fact to. find so many examples of seborrhea capitis without resulting loss of hair, especially as this condition had existed for many years in many of these people-disconcerting because in this paper it has been inferred, at least, that dandruff is the most frequent cause of alopecia. Nevertheless, when the data are put into cold figures it will be found that these inferences are perlaaps not wholly wrong. In the list there are 115 cases of alopecia simplex or a total number of 232 individuals in whom dandruff has played no part in the production of loss of hair. On the other hand, there is a total of $4.43 \mathrm{men}$, women, and children, a ratio of nearly two to one, in whom dandruff and loss of hair were present and in whom, by the figures in the great majority of instances, the seborrhea had preceded the alopecia for varying lengths of time.

To return to our cases of seborrhea simplex. Of the 117 examples 54: were males and 63 females, a ratio of 4.6 to 54-a distinct feminine preponderance and curiously enough corresponding absolutely exactly to our percentages of alopecia from various causes recorded in the early part of this communication (see above).

\section{Age When Seborrhea Began} J3etween 31 and 35,7 cases Between 36 and 40,4 cases Between 42 and 46, 2 easeg Bad, $\theta$ cases

\section{Males, 32 cases}

At $1,11,14$ euch, 1 case Jetween 16 and 20,8 cases Between 21 and 25, 2 cases Between 26 and 30,10 cases Between 36 and 40, 4 cases Between 53 and 60, 4 eases At 65 l case

Good, 93 cases

Between 11 and 14, 4 cases Between 16 and 20, 7 eases Between 21 and 25, 10 cases Between 26 and 30, 15 cases Between 31 and 35,16 cases Between 30 and 40,12 cases Between 41 and 45, 7 cases Between 46 and 50, 4 cases Between 51 and 55, 3 cases Between 57 and 60, 3 cases At $63,80,83$ each, 1 case

Between 11 and 15, 2 cases Between 16 and 20, 2 eases Between 21 and 25, 3 cases Between 26 and 30,6 cases Between 31 and 35, 4 cases Between 36 and 40, 2 cases At $50,56,60 \quad 2$ cuses Poor, 25 cases

These are rather small figures from which to draw conclusions but one is struck by the fact that dandruff comes on in childhood or in early adult life- 71 per cent. in men and 96 per cent. in women exhibiting this symptom at or before the age of 30 .

\section{Incidence of Seborrheic Symptoms Other Than Dandruff}

For some years it has been my custom to regard seborrhea as merely the cutaneous evidence of some internal disorder and to look on acne vulgaris, acne rosacea, eczema seborrheicum and Fordyce's disease of the lips as similar expressions of the same general disturbance. So, from a study of these records, I find that in the 443 cases of alopecia furfuracea there were 57 individuals (a percentage of 12 , consisting of 31 males, and 20 females) who exhibited one or more of these allied eruptions; while in the 117 examples of seborrhea simplex there were 29 men and 38 women (a total of $6 \%$, or a percentage of 57 ) with similar efflorescences. 


\section{DY'SPERSIA}

As to the nature of the fundamental disorder which, some think, lies at the bottom of these seborrheic symptoms we are decidedly at sea. Many of us, however, are wont to accuse digestive disturbances as possible sources of trouble and in this series of cases clinical evidences of dyspepsia have been found in the following percentages: in alopecia simplex 3 ; in alopecia furfuracen 8 ; and in seborrhea simplex 1\%. Surely, these are small crumbs of comfort to the believers in the digestive origin of these disorder's.

\section{Regions Affected in Alopecia Areata and in Ringworm} ALOPECIA AREATA, 80 CASES

Scalp, 71 cases

Occipital, $\quad 36$ enses $=50 \%$ Parietal, 11 cases $=15 \%$ Top of head, 8 crses $=11 \%$ Frontal, General, 11 cases $=15 \%$ 5 cases $=7 \%$

Ringworm, 9 cases

Occiput, 5 cases $=55 \%$
Top of head, 2 cases $=22 \%$
Sides, 1 case $=11 \%$
Beard, 1 case $=11 \%$
Face, 21 cases
Jeard, 13 cases $=02 \%$
Upper lip, 5 cases $=24 \%$
Eyebrows, 3 cases $=14 \%$

No comment is necessary on these figures; they are very small but they speak for themselves. In scrutinizing my cases of alopecia areata I was struck by the marked incidence of an accompanying dandruff. This statement of course coincides with Sabouraud's dictum that pathologically and bacteriologically seborrhea always precedes or accompanies alopecia areata. Another fact impressed on my mind in the study of these cases is that one attack of alopecin areata very often leads to one or more successive outbreaks.

\section{SUMMARY}

This then brings me to the end of these numerous columns of figures and deductions, which in conculsion I may summarize as follows:

1. Alopecia accompanied by dandruff is the commonest type of loss of hair.

2. Women are more prone to alopecia than men, in the proportion of 54 to 46 .

3 . The possible and principal causal factors of alopecia are heredity in 30 per cent., dandruff in 79 per cent., systemic depression in 20 per cent, fever in 11 per cent., and maltreatment of the scalp in 50 per cent.

4. Alopecia simplex develops before the age of 30 in 84 per cent. of the men, but in only 33 per cent. of the women.

5. Dandruff behaves in a similar manner and before the age of 25 attacks 61 per cont. of its future male victims but only 32 per cent. of its female.

6. The loss of hair in alopecia furfuracea comports itself with these previous two findings, appearing before the age of 25 in 67 per cent. of the men, but only in 34 per cent. of the women.

7. Summarizing paragraphs $2,4,5$, and 6 , we find that men are attacked earlier than women with alopecia and with seborrhea but that eventually women rather than men fall victims to these conditions.

8. When dandruff is present it is apt to be abundant rather than slight, oily ratlser than dry, and to be accompanied by itching.

9. With alopecia we find well-marked cases rather than mild ones, located in the great majority of the cases in the frontal and temporal regions and accompanied by hair which is apt to be dry, split, short and fine.
10. The drugs most successful in the treatment of dandruff and loss of hair are euresol, bichlorid of mercury, tamnic acid and chloral hydrate.

11. The final results of treatment in these affections are almost disheartening, but judged from a temporary point of view, we may expect good or very good response in 48 per cent. of men and in 56 per cent. of women.

12. Seborrhea may exist for years without entailing any appreciable loss of hair; nevertheless, dandruff does seem to be followed or accompanied by alopecia twice as often as not.

13. Seborrhea simplex is a disease of childhood or early adult life, developing before the age of 30 in $\% 1$ per' cent. of men and 96 per cent. of women.

14. Other seborrheas of the skin such as acne rulgaris, acne rosacea, eczema seborrheicum and Fordyce's disease, may accompany loss of hair and dandruff. Their percentages of concomitance, however, vary, and consist of 12 per cent. in alopecia furfuracea and $5 \%$ per cent. in seborrhea simplex.

15. Dyspepsia, on the other hand, exists in surprisingly small percentages in these cases, being present in only 3 per cent. in alopecia simplex, 8 per cent. in alopecia furfuracea, and 17 per cent. in seborrhea simplex.

16. From the preceding two paragraphs we may induce that seborrhea simplex is a truer form of dandruff than that accompanying loss of hair.

17. In alopecia areata and in ringworm of the scalp, the region most affected is the occipital.

18. In alopecia areata dandruff is a frequent accompaniment and we also find that one attack of the disease is apt to be followed by one or more later outbreaks.

250 Marlborough Street.

\section{ABSTRACT OF DISCUSSION}

Dr. William O. Roop, Dayton: I indorce Dr. White's statement in regard to the value of euresol in treatment of these diseases of the scalp. I have frequently included it in my application in the treatment of these seborrheic conditions, and it has given me better results than some of the older remedies.

I have been consulted during the past year in several cases of alopecia areata, and in all I was particularly struck by the accompanying seborrhea; and while the recognized treatment has always been of a stimulating character, I felt that inasmuch as the etiology of alopecia areata is somewhat in dispute, that perhaps the same treatment as for scborrhea, and of a less stimulating character than that usually employed, might be successful. With that idea in view, I used a simple ointment of sulphur and resorcin, rubbing it into the patches at night, and in a number of instances $I$ have been rewarded by a rapid return of hair in these bald areas. In other cases I have used treatment of a more stimulating character, such as applications of chrys. arobin, phenol and the high-frequency current, but I was surprised to observe that my results were more rapid and sntisfactory from use of the milder methods. This wonld suggest that alopecia areata may be of seborrheic origin since the two affections are so frequently concurrent and both yield to the same treatment.

Dr. Frank C. Knowles, Philadelphia: In anticipation that Dr. White would dwell on the subject of alopecia arenta, I have reviewed the dispensary reports of four hospitals, the Pennsylvanin, University of Pennsylvanin, Howard, and Children's, with which I am connected. During the last five year's I have seen 105 cases of this disease, twelve of this number being of the universal type. Alopecia arenta of dental origin has recently been reported by several writers; Jacquet has written most extensively on this phase of the subject. 
Bousseau-Decelle (Bull. et mém. de la Soc. méd. des hôp., 1909, p. (62) has deseribed several eases. Jourdanet (Bull. de la Soc. francaise de dermat. et de syph., April, 1910), detailed an alopecia areata of the nape of his own neek following caries of a wisdom tooth. Traumatism seemed to have been etiologic in a few of my cases. In my collection of photographs are five pictures of a case of universal alopecia, in a boy of sixteen. The various stages and relapses of the disease, extending over a period of three and one-half years, are plainly shown. The last photograph, which was taken in May, 1910, shows complete restoration of all the hair.

Dr. J. M. KING, Nashville: Dr. Whitfield, of King's College, London, who has the reputation of being a very careful and competent observer, lins found some defect of vision in nearly all his patients with alopecia areata. I remember that whenever such a patient consulted him, he always had the vision tested. In treatment, the preseription that I have used, in alopecia of the seborrheal type has been made up of bichlorid of mexcury, resorein, chloral hydrate, tincture of cantharides, glacial acetic acid and alcohol. I first saw this used in St. George's Hospital, London, and I found that it acted very well indeed in a number of cases. I have not tried euresol, as this mixture has served me well in conjunction with sulphur ointment, used onee every weck or two weeks, the night before the application of green sonp shampoo.

Dr. Alfred Schaler, Omalia: I was surprised to hear that seborrlea was an incurable disease, as my experience has not borne that out. I believe that it is curable in the majority of cases if the treatment is sulficiently prolonged. In one case of alopecia areata in which I applied the highfrequency current, the coincident seborrhea of a severe type from which the patient was also suffering largely disappeared, and from that time on I have used the high-frequency current in these cases with good results.

DR. J. J3. Kessi.er, Iowa City: The statement made by Dr. White that alopecia was more common in females than in males rather took me by surprise. My experience has been the reverse. In the hospital with which I am connected there are about 45 nurses in the training-school; after they lave been in the lospital six or eight months many of them complain that they are losing their hair. Last summer, in connection with some of my colleagues, I took up this matter to see if the cause of this loss of hair conld be determined. We investigated the cooking and the quality and quantity of the food, which was up to the average and sufficiently nourishing, and the only possible etiologic factor we could find was a lack of exereise in the open air. These nurses were on continuous duty for twelve hours and then returned to the Nurses' Home to sleep and study. It seems to me that this is the most prolific cause of alopecia in this class of people. I believe that women, as a rule, take better care of their hair than men, and when the hair becomes affected they are apt to follow the physician's directions more faithfully than men.

I have lad some experience with euresol, and while it is very efficient, it is also very expensive, $\$ 1.00$ an ounce making the price almost prohibitive. I lave found, usually, in these forms of alopecin, that ointments are better in the beginning than solutions, and that the latter are more effective when they are preceded by the use of ointments. A favorite application of mine-although its odor is objection. able-is the oil of cade and sulphur. I first learned the value of this nixture while $I$ was in Boston, working under the elder Dr. White. Euresol was brought to my attention through the kindness of Dr. Charles J. White; my results with this remely, as well as those of my son, have been very satisfactory. I keep up the application for about a month, when the dandruff can be easily removed and the scalp will remain free from it for a reasonable length of time. There are some cases, however, and I have one under my observation at the present time, in which all methods of treatment are more or less unsatisfactory.

Dr. Isapore Dyen, New Orleans: I want to sound one note in the danger of the use of the latir brusl. I lave preached for many years that no patient with dandruff will recover until the hair brush is discarded. There are only two ways of sterilizing it: One is by boiling and the second is by burning it. In the propagation of dandruff, the barber-shop is probably the chief offender, and I believe that an inspection of the usual ancient hair brush found in the wash-room of the country hotel or in any public place will demonstrate the destruction of the bristles of the brush itself by the micro-organism. The men who are interested in the work of this Section, as well as all dermatologists, should carry on this crusade against the hair brush as I have long done in my own city. I lave frequently seen patients in whom the recurrence of dandruff invariably followed $a$ visit to the barber shop. While on a visit aboard, after I had been free from dandruff for many years, I visited a burber shop and warned the barber not to use the brush. Just as he was completing his work, however, he forgot my instructions and gave one stroke with the lair brusl. Five days later I again began to treat my scalp for dandruff. I cannot concede that the particular form of seborrhea which we call dandruff is incurable. I instruct male patients to wash their sealp every day; the female patients every other day, or at least twice a week. An experience extending over a number of year, has justified my faith in the use of resorcin, 2 to 5 per cent. solutions. Euresol has no advantage over this, in my own experience. In fair-haired patients, or those who have hair tinged with gray, the resorcin must be modified or some substitute employed. By neglecting this precaution, I have once or twice in my early experience inflicted on my patients hair which in color resembled the plumage of a canary bird. Chloral lyydrate serves in these cases: it is an excellent stimulant to the scalp and an eficient antiseptic. I have never seen a case of alopecia areata which I belicved to be parasitic, or in which I was not able to demonstrate a neurotic basis. I remember one case in which these bald patches recurred for nearly a year; the patient's occupation was that of a driver of a fire engine, and when he gave that up, his hair promptly and permanently returned.

In the treatment of this condition, I regard the high-frequency current as more satisfactory than any other.

D12. M. I. Hemongsrem, Cincinnati: The basis of our present treatment of alopecia rest on the experiments of Lassur and Bishop, which were carried on 30 to 40 years ugo on mice, rabbits and other animals. For fifteen or 20 years the results of this work were unquestioned: when they were controverted by Blaschko, who maintained that alopecia was not a parasitic condition. Blaschko carried ont a series of experiments similar to those of Lassar and Bishop, and his results were absolutely negative. Treatment of this condition at the present time is based largely on the theory that it is of parasitic origin. Personally, I concur in the belief that premature baldness is not a parasitic condition. I think that too much manipulation of the scalp by rubbing and massaging is injurious both in men and in women. Premature balclness is accompanied by four cardinal symptoms, i. e., itehing, dandruff, a dry or oily condition of the scalp, and, lastly, loss of hair. Dandrufr is only a precursor of the loss of hair, and in order to prevent the occurrence of the latter, we must control the itching, the dandruff and the abnormal condition of the scalp. Treatment must be directed against these special conditions. Resorein, if too strong or ton frequently applied, will produce an oily condition of the sealp. An oily sealp may be rendered less oily, or even dry, by substituting colloidal sulphur or nascent sulphur. after the formula of Radcliffe Crocker for the resorcin.

Dr. Winriam Fricr, Kansas City: In the alopecia accompanying syphilis the loss of hair is not always limited to the scalp. I recently saw a case in which the alopecia of the sealp was not complete, but there was a complete losa of the eyebrows and eyeluslies.

Dir. Wirtiam A. P'usey, Chicago: One factor in regard to alopecia has not been mentioned and is worthy of consideration, particularly with the present fashion, and that is, excessive exposure of the scalp to sunlight. We are all familiar with the middle-aged man riding horsoback or playing golf bareheaded in the forlorn hope of bringing his hair buck. For many years I have regarded this excessive expos. 
ure to sunlight as an exciting factor in the production of alopecia. I huve noticed that many of these patients apply for treatment in the autumn, after they had gone bure headed throughout the summer, and I. was also led to this idea through the analogy of the effect of the sun's rays with those of the $x$-rays. We know that with highly actinic energy we ean produce baldness, and I am inclined to believo that free exposure to sunlight will have the same effect. This is probably only one of many factors, and in my opinion alopecia is a condition of complicated etiology; it is not a well-grounded view that all alopecias or nearly all aro parasitic.

I lave never been able to convince myself of the value of many of the remedies that lave been mentioned in the treatment of this condition. This is true of resorein, with which I have had a very unsatisfactory personal experience. I know of only two remedies that have a definite value in the treatment of alopecia, namely, tar and sulphur. I have used alcohol in various combinations, and it is my impression that nbout as much good is accomplished by nicohol alone as when it is combined with other remedies.

Dr. J. Grinuon, St. Louis: It is a popular notion that frequent washing injures the scalp, but practically, I have obscrver that those who are the most inveterate and constant in the practice of wasling the scalp keep their hair as long as anybody else, and I always tell my patients that they can wash their hends as often as they please. Nor can I understand how tive application of soap and water to the surface of the scalp can have any bad effect on the growth of the hair. In regard to medication in these cases, I have had very good results from the use of resorcin, and I agrec witl Dr. Kessler that solutions are usually more effective when they are preceded by the use of ointments. One of my favorite prescriptions is composed of petrolatum, salicylic neid and sulphur. I tell my patients that this application is disagrecable, but that it will probably not be necessary to continue it for longer than a month. After this I use resorcin, usually a 2 per cent. solution, either alone or in combination. In cases of well-cstablished seborrheal alopecia I tell my patients that I do not believe that I shall ever be able to give them an actual permanent cure, but that I lope to bring about a symptomatic cure, providing they keep up the treatment inclefinitely. As long as they live they will be obliged to pay some attention to the scalp in order to avoid a recurrence. So far as the effect on the scalp of exposure to the rays of the sum is concerned, I must agree with Dr. Pusey on theoretical grounds. The comparative frequency with which cases of loss of hair are observed in the autumn I attribute not to the effect of the sun's rays, but rather to the fact that there is natural loss of hair at that period of the year, whether one plays golf bareheaded or not. The *-ray, in small doses, causes a growth of hair, while large doses produce a loss, and the actinic rays from the sun in such doses as we get them, probably stimulate the growth of hair. Our ancestors, who wore no clothing at all, had hair all over their bollies.

Dr. J. B. Kessler, Iowa City: J lave in mind a case of universal alopecia in a boy of 18 in whom the condition has now lasted about 2 years. With tlie exception of two or three little stubs, his body and scalp are completely bare. He has beeen examined by a neurologist and his blood has been examined with entirely negative results. I have been unable to find the cause of the alopecia or a remedy for it.

Dlk. Frances Rowley, Galveston: Has anyone studied this matter with reference to the diet of the patient? Has the nitrogenous metabolism been investigated, or would these patients receive any benefit by increasing the sulphur?

DR. C. J. WHITE, Boston: The diversity of opinions expressed well illustrates the fact that we really do not know anything about this subject scientifically. We have our pet theories, and we reason largely by analogy. I agree with $D_{r}$. Pusey in regard to the eflect on the hair of over-exposure to sunlight. I belicve that the scalp and hair are supposed to have a certain amount of grease, and if we expose the scalp to the sun, we remove the grensy element and the hair becomes bleached. For the same reason, constant washing of the head or over-treatment of the scalp is equally disadvantageous. This history of too much sun or too much washing I bave frequently obtained from persons who were prematurely bald.

My colleagues and $I$ in Boston have never derived much benefit from the use of resorein in this disense. If it is applied strong enough to do any good, it inflames the scalp. As to $\Omega$ possible deficiency of sulphur in the economy, to which Dr. Rowley referred, I do not know whether any scientific work has been done in that direction, but I have given that drug internally in one of $j$ ts several forms with. out resulting benefit.

I tell my patients to use a hair brush as little as possible unless it is a clean one, and instruct them to sterilize it by plucing it in the sun for a few hours at least once a week. agree with Dr. Dyer that the hair brush is a very common calse of the persistence of dandruff. In trentment in general, I have tried all the various ointments, and in my hands they did not work so well as the two lotions that I have described. I belicve that women are affected with alopecia oftener than men, but there nre cases in which men feel more keenly than women the loss of their hair. As to the varions etiologic factors of nlopecia arenta referred to by Dr. Knowles, I do not think we know the true eause of the affection, but I believe that in some specific organism plus the stimulus of a nervous breakdown or sudden shock or the debilitnting effect of slow sepsis from carious tecth we have a reasonable theory of the origin of this disease.

\section{THE EXTERNAL PREPARATIONS OF THE \\ U. S. P. AND THE NATIONAL FORMULARY *}

\section{S. N. HALLBERG, Phm.l)., M.D. CHICAGO}

the U. S. PIIARMacopeia

The external preparations of the U. S. P. comprise some 55 articles representing the following classes:

$\begin{array}{cc}\text { Unguenta } & \text { Linimenta } \\ \text { Cerata } & \text { Collodia } \\ \text { Suppositoria } & \text { Cataplasma } \\ \text { Oleata } & \text { Chartre }\end{array}$

Previous to the last revision these preparations were designed from a purely pharmacal stand point: that is, the selection of the vehicle-the forming substancewas governed primarily by pharmaceutic considerations, so as to insure stable and otherwise superficially satisfactory preparations.

Having immediate charge of these preparations in the last revision, it was our good fortune to receive suggestions from many medical specialists, ophthalmologists, gynecologists and dermatologists, such as Dr. W. L. Baum of this Section, and the formulas for these preparations were for the first time revised on a therapeutic basis. Since they have proved uniformly satisfactory pharmacentically, it might be well here briefly to consider these preparations according to their classification and therapeutic groupings, in order to determine whether practice has demonstrated the correctness of the theoretic considerations on which they were severally formulated, and it is hoped that the fullest discussion and criticism may obtain among those who usc these preparations. *The nuthor of this paper, being now engaged In the revision
of the I. S. I. and the N. F., deslres physfelans to report to bium any critlelsm on these preparations, particularly the newer ones taken from the British Codex, and also any additions that might be suficiently valuable or extensively used to warrant admight to elther the U. S. I'. or the N. F. Address C. S. N. Haldbel'sion iv. Twelfth street, chicago, IIt.

* liead in the Section on Dermatology of the cal Assoclation, at the Sixty-arst Annual of the American Med June, 1010. 